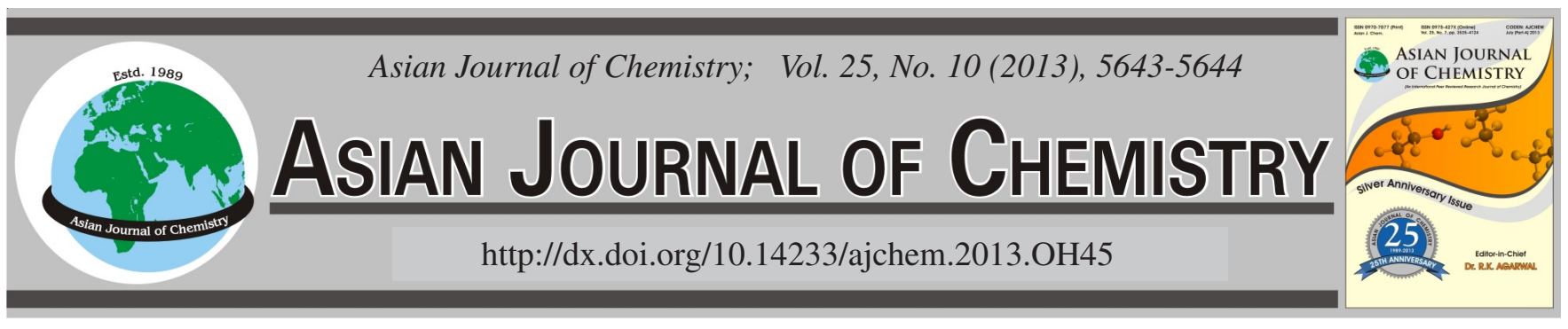

\title{
ZnO Powders for Rapid Removal of Cu(II) Ions in Solution $\dagger$
}

Chengliang Han*, Genhui Wang, Wenlong Zhao, Tianran, Chunhui Chen and Huwei

Department of Chemical and Material Engineering, Hefei University, Hefei 230022, P.R. China

*Corresponding author: E-mail: clhan@issp.ac.cn

$\mathrm{ZnO}$ powders prepared by direct oxidation of $\mathrm{Zn}$ powders were used to remove $\mathrm{Cu}(\mathrm{II})$ ions in wastewater. Results showed that the as-prepared $\mathrm{ZnO}$ powders had an irregular sheet shape and each sheet was packed with many nanorods. Sorption experimental results indicated that $\mathrm{ZnO}$ powders could remove effectively $\mathrm{Cu}$ (II) ions in water. The equilibrium sorption isotherm of $\mathrm{Cu}$ (II) on $\mathrm{ZnO}$ has been analyzed by the Freundlich, Langmuir and Redlich-Peterson isotherm equations.

Key Words: ZnO powders, Adsorption, Oxidation, Isotherm models.

\section{INTRODUCTION}

$\mathrm{ZnO}$ crystals are known with various morphologies such as microspheres, nanobelts, nanosheets etc., have been applied in sensors ${ }^{1}$, catalysts ${ }^{2}$ and dye-sensitized solar cells ${ }^{3}$. However, the reports about the application of $\mathrm{ZnO}$ powders in wastewater treatment are seldom in present.

In this article, we report that $\mathrm{Cu}(\mathrm{II})$ ions in solution can be rapidly and effectively removed by $\mathrm{ZnO}$ powders at room temperature. Various sorption isotherms were used to evaluate the experimental data.

\section{EXPERIMENTAL}

$\mathrm{ZnO}$ powders were prepared by direct oxidation of $\mathrm{Zn}$ powders precursor at $700{ }^{\circ} \mathrm{C}$ for $3 \mathrm{~h}$. X-ray diffraction patterns were measured on a Philips X'pert diffractometer using $\mathrm{CuK} \alpha$ radiation $(0.15419 \mathrm{~nm})$. Morphology of the product was observed on a Sirion 200 FEG field emission scanning electron microscope.

Adsorption experiments were carried out by agitating $1 \mathrm{~g}$ of $\mathrm{ZnO}$ with $100 \mathrm{~mL} \mathrm{Cu}$ (II) ion solution in a shaker at $25^{\circ} \mathrm{C} /$ $120 \mathrm{rpm}$. The initial $\mathrm{pH}$ value of the solutions was $6.0 \pm 0.5$. The reaction time $(0.5 \mathrm{~h})$ was shown to be adequate by preliminary experiments for equilibrium to be attained. The samples were withdrawn from the flasks at predetermined time intervals and analyzed for $\mathrm{Cu}$ (II) content by hydride generation atomic absorption spectrophotometry (ICP-AES). The adsorption capacity of the $\mathrm{ZnO}$ for $\mathrm{Cu}$ (II) was calculated through the following equation:

$$
\mathrm{q}_{\mathrm{e}}=\frac{\left(\mathrm{C}_{0}-\mathrm{C}_{\mathrm{e}}\right) \mathrm{V}}{\mathrm{m}}
$$

where $\mathrm{q}_{\mathrm{e}}$ is the amount of $\mathrm{Cu}(\mathrm{II})$ adsorbed at equilibrium $(\mathrm{mg} / \mathrm{g})$, $\mathrm{C}_{0}$ and $\mathrm{C}_{\mathrm{e}}$ is the initial and final concentration of $\mathrm{Cu}(\mathrm{II})(\mathrm{mg} / \mathrm{L})$, $\mathrm{V}$ is the volume of $\mathrm{Cu}(\mathrm{II})$ solution $(\mathrm{mL})$ and $\mathrm{m}$ is the mass of the used $\mathrm{ZnO}(\mathrm{g})$. All assays were carried out in triplicate and the average was used in the analysis.

\section{RESULTS AND DISCUSSION}

Phase and morphology of the absorbents: The corresponding XRD of as-prepared $\mathrm{ZnO}$ nanomaterials is illustrated in Fig. 1. The diffraction peaks match well with the standard values of $\mathrm{ZnO}$ (JCPDS NO.89-1397), indicating that the as-prepared products are $\mathrm{ZnO}$ phase.

From the SEM image of Fig. 1b, it can be found that the as-prepared $\mathrm{ZnO}$ nanomaterials prepared from oxidation
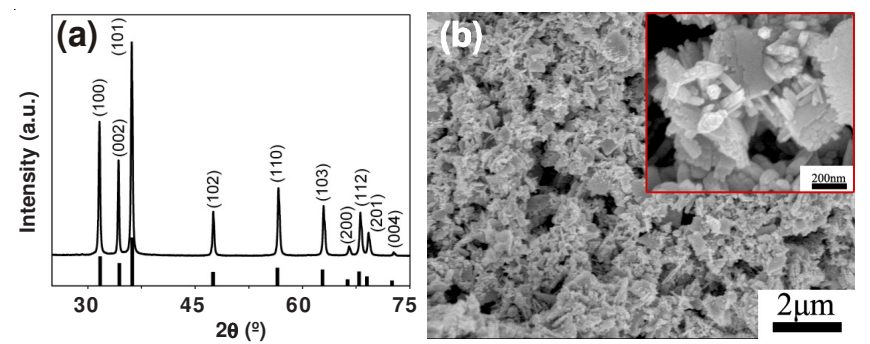

Fig. 1. (a) XRD patterns of the as-synthesized product and standard $\mathrm{ZnO}$ powders (the line spectrum), (b) Morphology of the as-prepared $\mathrm{ZnO}$ powders 
of $\mathrm{Zn}$ powders precursor have irregular sheet morphology, the sheets are packed with many finer rods and have a rough surface. The size of each sheet is about 0.1-0.3 $\mu$ m (inset of Fig. 1b).

Equilibrium studies: Adsorption isotherms are basic requirements for the design of sorption systems. These data provide information about the capacity of the adsorbent or the amount required for removing a unit mass of pollutant under the system conditions. The equilibrium adsorption isotherm analyses were performed by plotting copper ions adsorbed $\left(\mathrm{q}_{\mathrm{e}}\right)$ against the equilibrium concentration of copper ions $\left(\mathrm{C}_{\mathrm{e}}\right)$ in solution (Fig. 2).

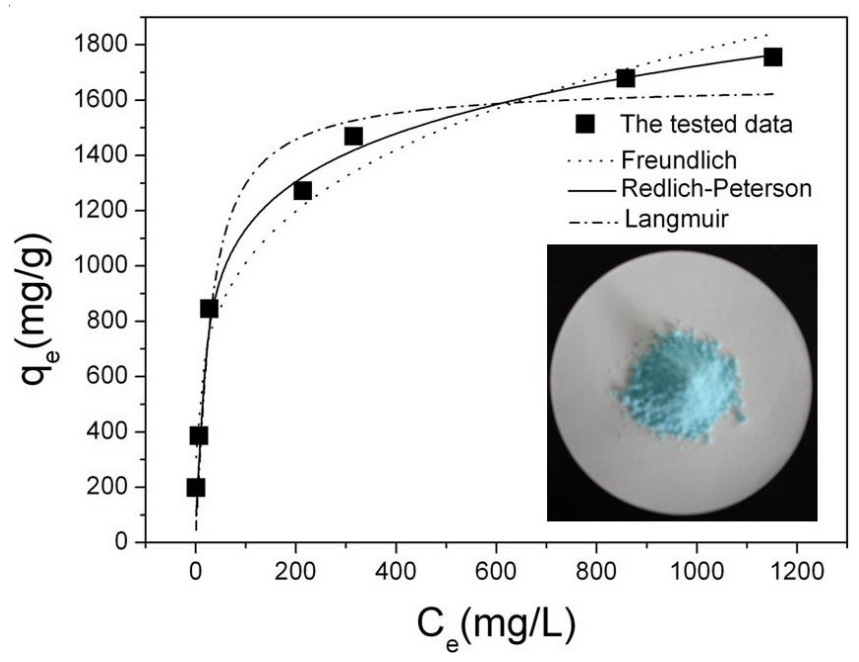

Fig. 2. Adsorption isotherm of $\mathrm{Cu}(\mathrm{II})$ on $\mathrm{ZnO}$ powders (inset: color of $\mathrm{ZnO}$ powders after adsorption for $0.5 \mathrm{~h}$ in $100 \mathrm{~mL}$ solution with $\mathrm{Cu}$ (II) concentration of $500 \mathrm{mg} / \mathrm{L}$

It is well known that the Langmuir sorption isotherm is the best known of all isotherms describing homogeneous sorption, where the sorption of each adsorptive molecule onto the surface has equal sorption activation energy. And the Freundlich isotherm is most frequently used to describe the heterogeneous adsorption of inorganic and organic components in solution. The Redlich-Peterson isotherm contains three parameters and incorporates the features of the Langmuir and the Freundlich isotherms.
In order to further understand the best correlation of equilibrium data. The theoretical Langmuir ${ }^{4}$, Redlich-Peterson ${ }^{5}$ and Freundlich ${ }^{6}$ isotherms were respectively plotted using a dash dot, a solid and a dot line shown in Fig. 2 comparing with the experimental scattered data points. Comparing with each other, the Redlich-Peterson equation which incorporated the features of the Langmuir and Freundlich isotherm models represents the best fit of experimental data than other equations.

From the inset of Fig. 2, we can vividly see that the color of $\mathrm{ZnO}$ powders after adsorption for 30 mins in $100 \mathrm{~mL}$ solution has become blue. This phenomenon well indicates that the white $\mathrm{ZnO}$ powders can effectively and rapidly adsorb $\mathrm{Cu}$ (II) in aqueous solution.

\section{Conclusion}

$\mathrm{ZnO}$ powders could be used as an effective adsorbent for removal of $\mathrm{Cu}(\mathrm{II})$ in wastewater. The equilibrium sorption isotherm of $\mathrm{Cu}$ (II) on $\mathrm{ZnO}$ was identified as the RedlichPeterson isotherm equation. $\mathrm{ZnO}$ materials are expected to be applied in water environment treatment.

\section{ACKNOWLEDGEMENTS}

This work was supported by Natural Science Foundation of Education Department of Anhui Province (project number KJ2012B148, KJ2012B154) and Undergraduate Science and Technology of Hefei University (project number 11XSKY04, 11 XSKY05) and Natural Science Foundation of Hefei University (12RC02).

\section{REFERENCES}

1. J. Zhang, S.R. Wang, Y. Wang, M.J. Xu, H.J. Xia, S.M. Zhang, W.P. Huang, X.Z. Guo and S.H. Wu, Sens. Actuators B, 139, 411 (2009).

2. Q.Y. Li, C.L. Wang, M.L. Ju, W.L. Chen and E.B. Wang, Micropor. Mesopor. Mater., 138, 132 (2011).

3. J.X. Wang, C.M.L. Wu, W.S. Cheung, L.B. Luo, Z.B. He, G.D. Yuan, W.J. Zhang, C.S. Lee and S.T. Lee, J. Phys. Chem. C, 114, 31 (2010).

4. I. Langmuir, J. Am. Chem. Soc., 38, 2221 (1916).

5. H.M. Freundlich, Z. Phys. Chem. A, 57, 385 (1906).

6. O. Redlich and D.L. Peterson, J. Phys. Chem., 63, 1024 (1959). 